\title{
MAP Cartagena: metodología para el mapeo de asentamientos precarios usando OpenStreetMap
}

\author{
Natalia da Silveira Arruda* \\ Humberto Yances**
}

Recibido el 25 de febrero 2016; aceptado el 22 de septiembre de 2016

\begin{abstract}
This article describes the methodology created within the Pilot Project MAP Cartagena of TECHO NGO for slums mapping using OpenStreetMap, a global community that generates and releases geographic data as open data, considered the Wikipedia of maps. Narrates the sequential steps for creating and joining geographic and population data, generating as result relevant spatial indicators and maps of main problems exposed by communities. So that serve as input for the establishment of a community profile and ulterior intervention for community development.
\end{abstract}

Key words: digital and participatory cartographic, voluntary work, slums, community profile, community development.

\section{Resumo}

O presente artigo descreve a metodologia criada ao interior do Projeto Piloto MAP Cartagena, da ONG TECHO, para o mapeamento de assentamentos precários utilizando como meio de apoio OpenStreetMap, uma comunidade global que gera e libera dados geográficos como dados abertos, considerada a Wikipédia dos mapas. Narra os passos sequenciais para a criação e a junção de dados geográficos e populacionais, gerando como resultados indicadores espaciais e mapas pertinentes aos principais problemas expostos pelas comunidades, de modo que sirva como input

* Coordinadora del Proyecto Piloto MAP Cartagena en TECHO Cartagena, arquitecta y urbanista, máster en Planeación Territorial, Urbanística y Paisajístico-Ambiental, correo electrónico: nati.dsa@gmail.com

** Miembro Votante de Humanitarian OpenStreetMap Team (HOT), economista y máster en Gestión del Conocimiento. Asesor voluntario para la metodología de mapeo del proyecto MAP Cartagena, correo electrónico: humbertoyances@openstreetmap.co 
para o estabelecimento do perfil comunitário e fases posteriores de intervenção visando o desenvolvimento da comunidade.

Palavras-chave: cartografia digital y participativa, voluntariado, assentamentos precários, perfil comunitário, desenvolvimento comunitário.

\section{Resumen}

El presente artículo describe la metodología creada al interior del Proyecto Piloto MAP Cartagena de la ONG TECHO, para el mapeo de asentamientos precarios usando OpenStreetMap, una comunidad global que genera y libera datos geográficos como datos abiertos, considerada como la Wikipedia de los mapas. Narra los pasos secuenciales para la creación y unión de datos geográficos y poblacionales, generando como resultado indicadores espaciales y mapas pertinentes a los principales problemas que exponen las comunidades. De forma que sirva como insumo para la constitución de un perfil comunitario y ulteriores fases de intervención para el desarrollo comunitario.

Palabras clave: cartografía digital y participativa, voluntariado, asentamientos precarios, perfil comunitario, desarrollo comunitario.

\section{Introducción}

El Proyecto Piloto $\mathrm{MAP}^{1}$ Cartagena nace en 2015 a través de la iniciativa de un grupo de voluntarios de la ONG TECHO, con el objeto de responder a la demanda hecha por parte de algunos pobladores de Isla de León (comunidad que se encuentra en una situación de informalidad y subnormalidad), ${ }^{2}$ para nombrar y numerar sus calles y casas.

TECHO es una organización que busca superar la situación de pobreza en que viven miles de personas en los asentamientos precarios, fomentando el desarrollo comunitario a través de la acción conjunta de sus pobladores y jóvenes voluntarios. Inició en 1997, hoy (en 2016) la organización mantiene operaciones en 19 países de Latinoamérica y el Caribe.

En Colombia, TECHO decidió acercarse a la ciudad de Cartagena de Indias en 2008 construyendo viviendas de emergencia en el barrio Fredonia. Desde 2011 inició su proceso de consolidación en la ciudad trabajando en acción conjunta con

Mapeo de Asentamientos Precarios.

En Colombia un barrio subnormal es definido como un "asentamiento humano ubicado en las cabeceras de municipios o distritos [...] Que no tenga servicio público domiciliario de energía eléctrica o que este se obtenga a través de derivaciones del Sistema de Distribución Local o de una Acometida, efectuadas sin aprobación del respectivo Operador de Red” o “...donde esté prohibido prestar el servicio según lo previsto en el artículo 99 de la Ley 812 de 2003”. Según Decreto 3735 de 2003. 
jóvenes voluntarios y pobladores de los asentamientos más precarios, como Isla de León en el barrio El Pozón.

Después de un largo proceso de trabajo con esta comunidad a través de la construcción de viviendas de emergencia (primera y principal fase de trabajo de la organización), paulatinamente esta fue demostrando interés en recibir apoyo en temáticas hasta el momento desconocidas para ellos. Razón que gestó la idea de iniciar la fase de desarrollo comunitario subsecuente a los trabajos que venía desarrollando la organización. Apareciendo el requiriendo de un nuevo eslabón para la transición entre una fase y otra, es allí cuando se conforma entonces el Proyecto Piloto MAP Cartagena.

Debido a las características de informalidad y subnormalidad que presenta el asentamiento, se identificaron las mismas como el problema de fondo que conlleva a que la comunidad no tenga un sistema de nomenclatura en sus calles -el mismo problema que conlleva a la falta de todos los demás servicios públicos. Por su informalidad, Isla de León no aparece en ningún sistema de planeación urbana en la ciudad de Cartagena, ni en el sistema de catastro del IGAC, ${ }^{3}$ ni en la plataforma MIDAS. ${ }^{4}$ Partiendo de ese análisis previo, se decidió ampliar los objetivos del proyecto más allá de lo solicitado por la comunidad y abarcar el tema de que la comunidad de Isla de León no se encuentra en ningún sistema cartográfico.

El proyecto piloto surge de ese modo asumiendo como objetivo principal identificar, localizar y georreferenciar; no sólo el asentamiento informal de Isla de León como un todo, sino también cada calle y vivienda presente, conformándose este componente como un relevo posterior hacia la fase de desarrollo comunitario.

Otros objetivos del proyecto fueron involucrar a los pobladores de la comunidad como mecanismo participativo; integrar a las viviendas (como elementos espaciales) con datos de la Encuesta de Caracterización de Hogares (ECH) dentro de un Sistema de Información Geográfica (SIG); levantar el perfil de la comunidad, incluyendo su historia, describiendo el acceso a servicios públicos y su infraestructura y; por último, compartir el mapa, los datos y los resultados generados con la misma comunidad y al público en general través de una plataforma online.

De esta manera se espera fomentar la resiliencia y el desarrollo comunitario, de forma que la comunidad misma logre identificar sus problemáticas y buscar las soluciones pertinentes, empezando a preocuparse por su planeación y desarrollo.

En el proceso de desarrollo metodológico del proyecto piloto, el acercamiento al método y a las herramientas de trabajo del Equipo Humanitario de OpenStreetMap (HOT, por sus siglas en inglés), se dio a partir del conocimiento de la existencia de

3 El Instituto Geográfico Agustín Codazzi elabora y actualiza el mapa oficial de la República de Colombia. Ejecuta planes de gobierno en materia de cartografía, agrología, catastro y geografía.

4 Mapa interactivo de la ciudad que permite la consulta de la normativa referente al Plan de Ordenamiento Territorial de Cartagena. 
un proyecto de mapeo comunitario en La Boquilla (Yances, 2013), una comunidad de pescadores con cerca de 200 años de historia, cercana a la ciudad de Cartagena de Indias.

El entrelazamiento de las metodologías de trabajo de ambas instituciones constituyó un nuevo reto para el proyecto piloto: trabajar la información recolectada en campo de forma georreferenciada, creando una línea secuencial entre las diferentes actividades en las etapas del modelo de trabajo de la organización y permitiendo la constante visualización de los datos.

\section{Descripción del área geográfica de estudio}

La comunidad de Isla de León es un pequeño asentamiento precario de unas 10 hectáreas ubicado en el sector El Pozón, zona suroriental de la ciudad de Cartagena de Indias, colindante con la Ciénaga de la Virgen, una laguna costera ubicada sobre el sector norte de la ciudad y separada del mar por el cordón de arenas del corregimiento de La Boquilla. Tiene forma triangular, estrecha en el norte y amplia en el sur, con una anchura máxima de 4.5 kilómetros y una longitud de 7 kilómetros.

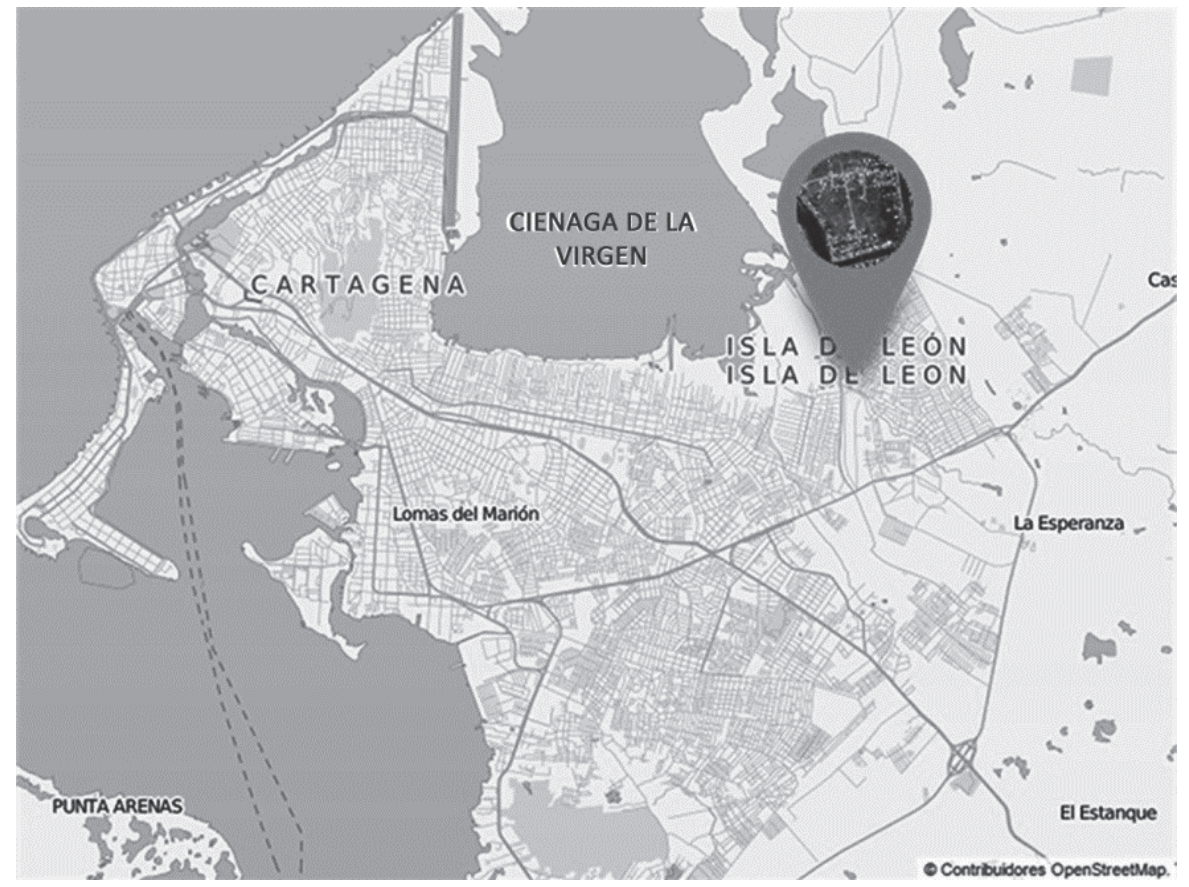

Figura 1. Localización del asentamiento de Isla de León en la ciudad de Cartagena de Indias.

Fuente: MAP Cartagena/OpenstreetMap. 
Durante varias décadas - y hasta antes de la entrada en operación del emisario submarino a finales de 2013 - , el 60\% de las aguas residuales domésticas de Cartagena, — - y actualmente - el sedimento producido por la erosión del cerro de La Popa y las basuras sólidas provenientes de caños interiores, desembocan en esta ciénaga. La zona suroriental de la ciudad, a orillas de la ciénaga, alberga al $30 \%$ de su población, en su mayoría desplazada, y constituye el área de mayor impacto en las épocas invernales (Arcieri G., 2005).

En el proceso de crecimiento no planificado de la ciudad, la exclusión sistemática de una parte de la sociedad conlleva no sólo a una exclusión social, sino también espacial. Para el año 2000, 69\% de los barrios que existían en Cartagena eran informales. Los asentamientos subnormales realizados durante los años sesenta, setenta y ochenta explican el $87 \%$ de la expansión registrada en la ciudad desde mediados del siglo pasado (Programa de las Naciones Unidas para el Medio Ambiente -PNUMA, 2009), estos tienden a concentrarse en áreas periféricas, donde el acceso al suelo debe darse a través de mecanismos alternativos, así como la satisfacción de las necesidades básicas.

Isla de León está rodeada por caños en tres de los cuatro lados de su perímetro, por lo cual frecuentemente se inunda, ya habiendo dejado a la comunidad completamente aislada durante la fuerte temporada invernal de 2010 por el fenómeno de La Niña. El asentamiento, separado del barrio El Pozón por un puente de cimiento y unos puentes de madera improvisados por la comunidad, erigido en terrenos donde antes crecían cultivos de arroz, empezó a poblarse durante la década de los ochenta por personas que venían de otros municipios de Bolívar o del resto del Caribe, la mayoría desplazados por la violencia, y fueron rellenando el cenagal con basuras y aserrín para levantar sus casas con materiales improvisados (Brito, 2008).

Isla de León es una comunidad que presenta un carácter muy dinámico en función de las repetidas ocupaciones que sufre, así como de los desplazamientos de los pobladores hacia otros barrios aledaños en los períodos de inundación. Similar a otras comunidades informales en Colombia, recibió y sigue recibiendo a muchas personas desplazadas de otras regiones del país. La mayoría vienen de modo forzoso por los problemas de la violencia.

El trabajo que ya venía desarrollando la ONG TECHO en los dos años de visita a Isla de León, permitió que se iniciara el proyecto con un cierto conocimiento previo de la comunidad, teniendo el apoyo y la confianza de los pobladores en los voluntarios. Asimismo, a pesar de tener un conocimiento significativo sobre la comunidad, en ese momento se creía que el asentamiento estuviera conformado por cerca 120 viviendas y no se contaba con ningún estudio socio-estadístico que recopilara la información existente. 


\section{Metodología}

Consta de tres etapas, una primera es la socialización de las metodologías técnicas con la comunidad, de forma que estas vayan alineadas a sus requerimientos, la segunda de cartografía voluntaria y; una tercera, para la integración de los datos geográficos con los datos poblacionales de la Encuesta de Caracterización de Hogares $(\mathrm{ECH})$, constituyendo este último enlace la novedad para la construcción del perfil comunitario, al usar datos geográficos abiertos de OpenStreetMap.

\section{Involucramiento con la comunidad}

Es un proceso interativo a lo largo de la ejecución, en cada uno de los hitos del proyecto se involucra a la comunidad. En primera instancia se presenta la metodología ante sus líderes o representantes; sino existe una asamblea de pobladores para la participación y validación de resultados, es en esta etapa donde se define una.

A partir de este establecimiento de equipos de trabajos mixtos, entre la ONG y la comunidad, continúan actividades de sensibilización, atendiendo a dos grupos diferenciados: un primer grupo con la comunidad adulta de Isla de León y; un segundo grupo con niños. Con la comunidad adulta se realizan actividades para la introducción a la lectura de mapas e imágenes aéreas, con el objeto de informar el alcance y el potencial de estas herramientas geomáticas en la planeación y desarrollo del territorio. La actividad de sensibilización con los niños estuvo enfocada en lo lúdico con un fondo claramente pedagógico. Se trabajó la lectura y ubicación de los niños en diferentes escalas territoriales, partiendo del mapa de Colombia hasta llegar a la escala del asentamiento, y, a través del dibujo, se trabajaron los mapas mentales que cada niño tenía de su comunidad, asociando elementos representativos del barrio, así como la caracterización de cada lugar en relación a sus sentimientos, sentidos, vivencias cotidianas y sueños.

\section{La cartografía digital voluntaria}

Para la generación de la cartografía digital y los datos geográficos, la metodología aplicada al proyecto piloto tuvo como base la guía de mapeo urbano creada por el proyecto Open Cities (The World Bank, 2014); adaptándola a las particularidades de la geografía y comunidad local, en especial la incorporación de técnicas para la obtención de imágenes aéreas desde globos y drones con el objeto de actualizar rápidamente la cartografía al presente, así como obtener las ventajas geomáticas al usar coordenadas de proyección (MAGNA-SIRGAS:EPSG-3116) para la medición de áreas de las viviendas. 


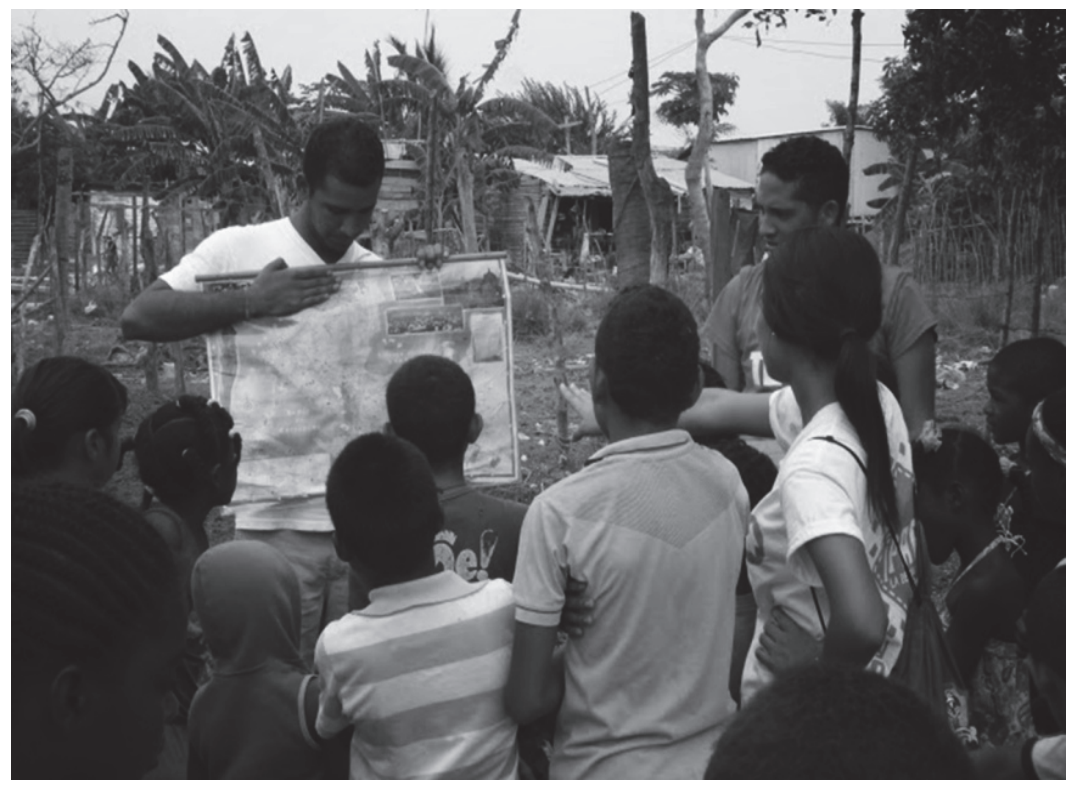

Figura 2. Taller de sensibilización, actividad lúdica con los niños. Fuente: MAP Cartagena.

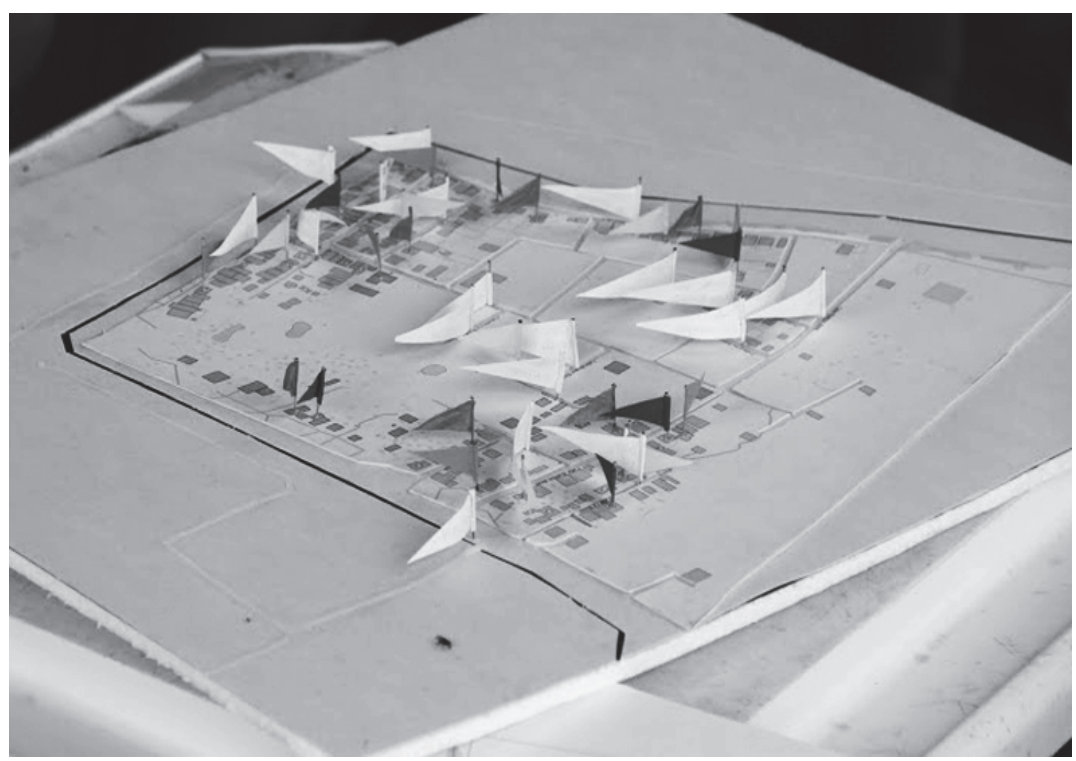

Figura 3. Actividad de involucramiento de la comunidad a través del reconocimiento de su entorno.

Fuente: MAP Cartagena. 


\section{Pasos de la metodología}

Generación de datos geográficos

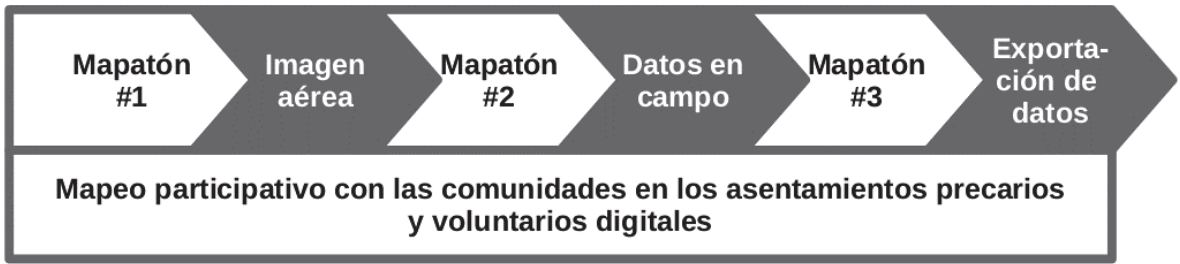

Figura 4. Pasos de la metodología para el mapeo de asentamientos precarios.

Los siguientes son los pasos de la metodología resultante aplicada:

\section{1er. Taller de Mapeo (mapeando el pasado)}

Tienen el doble propósito de mapear el estado del asentamiento precario en el pasado, a la vez, servir como proceso de entrenamiento para los voluntarios maperos y la comunidad sobre OpenStreetMap y sus técnicas de recolección de datos y coordinación de mapeo remoto, creando un proyecto en el Gestor de Tareas $(<\mathrm{http}: / /$ tareas.openstreetmap.co $>)$ y trazando la imagen con el software de escritorio Java OpenStreetMap editor (JOSM).

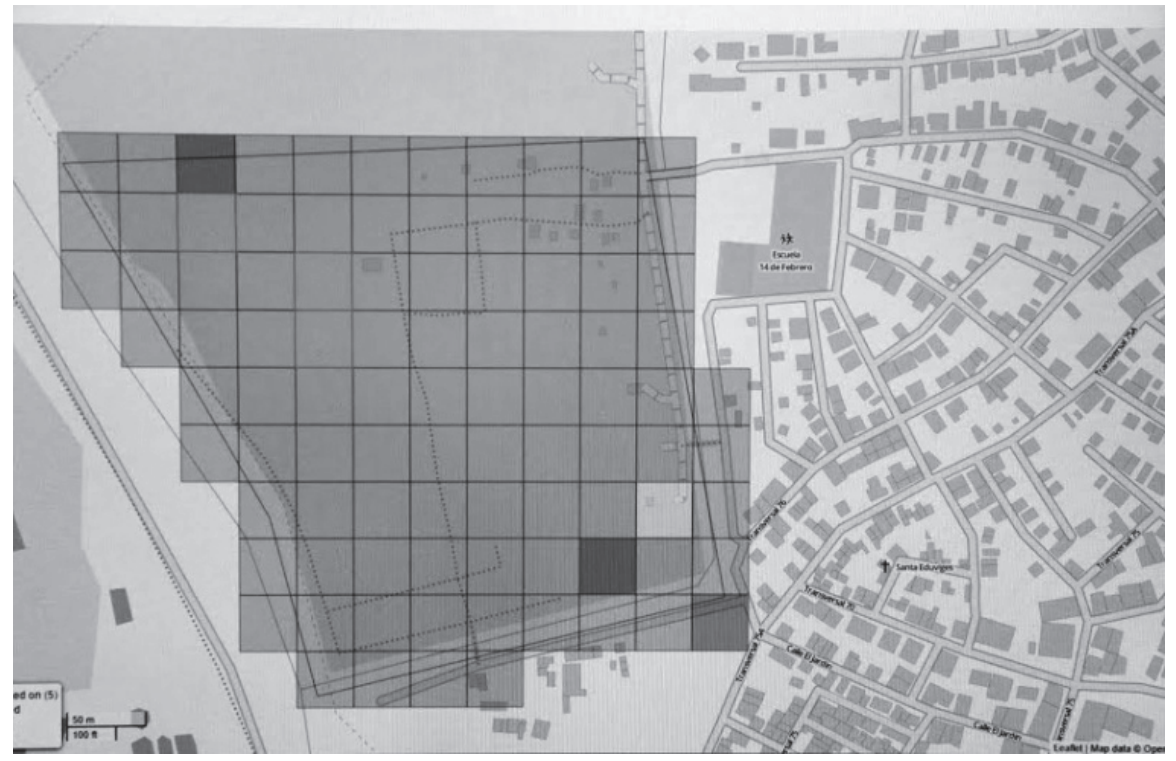

Figura 5. División del asentamiento en cuadrantes en el Tasking Manager para el 1er. Taller de Mapeo. 


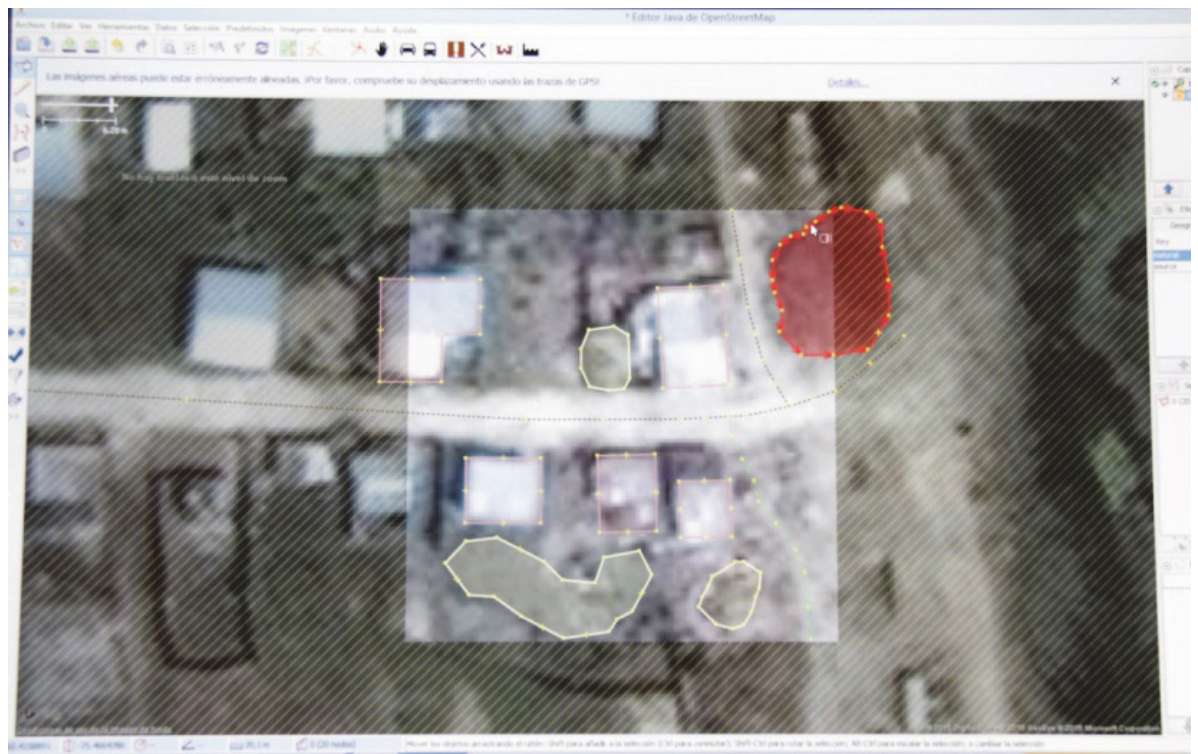

Figura 6. Uno de esos cuadrantes siendo trabajados en el editor de mapas JOSM.

\section{Captura y servido de imágenes aéreas}

Se usaron dos técnicas para evaluar cuál de las dos era la más costo-efectiva en asentamientos precarios. La primera fue usando globos rellenados con helio, siguiendo y adquiriendo la guía y productos (Balloon Mapping) de Public Lab $<$ https://publiclab.org/>. La segunda fue usando un drone multirotor (gracias a la donación de la empresa de filmación local Karmairí Producciones. El ejercicio quedó documentado en este video publicado en Youtube como resultados intermedios del piloto $<$ https://www.youtube.com/watch?v=vRRHAgxioZw $>$ ).

Siguiendo el flujo de proceso instaurado por la comunidad de OpenStreetMap Colombia, el conjunto de fotografías fue enviado a la comunidad de OpenStreetMap Francia para la unión del ortofotomosaico, su georreferenciamiento usando trazas GPX capturadas en campo y publicación en su servidor TMS para posterior calcado.

Se descarta el uso de globos debido a la dificultad de recorrido en asentamientos precarios, por las características de informalidad del tendido de redes eléctricas, el cercado de propiedades e irregularidad general del terreno. También los costos y logística de los tanques de helio dificulta la actividad y resultó muy oneroso para la calidad de las imágenes obtenidas. Se recomienda este método para áreas despejadas, quizás mejor para exploraciones aéreas en proyectos medioambientales en pequeñas áreas de extensión. 


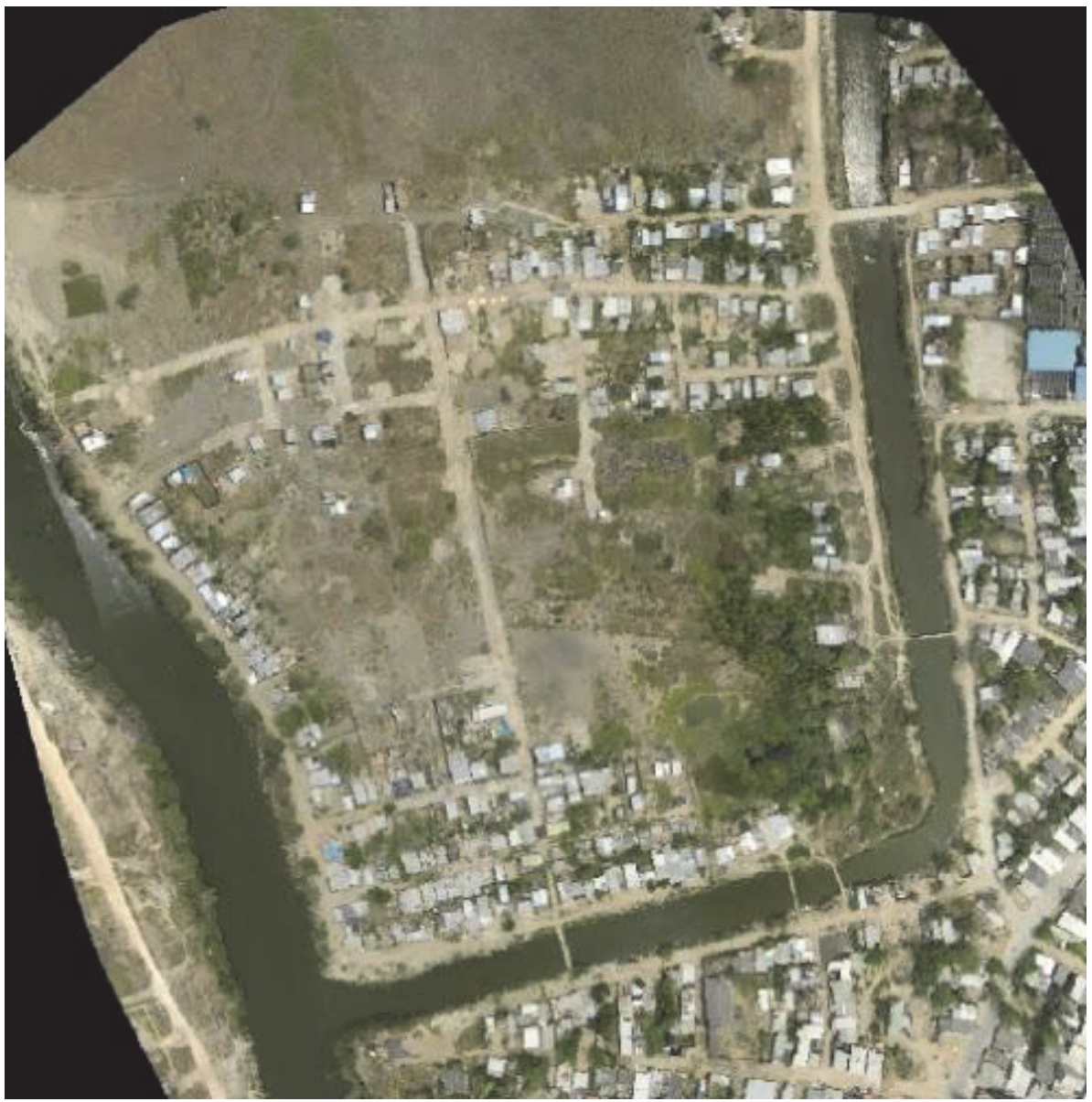

Figura 7. Ortofoto del asentamiento Isla de León.

\section{2do. Taller de Mapeo (mapeando el presente)}

El ortofotomosaico fue capturado el 12 de abril de 2015, por lo tanto en ese momento constituyó el tiempo presente del estado de las construcciones en Isla de León, con el objetivo de actualizar la realidad cartográfica del asentamiento, se realiza un segundo taller de mapeo agregando toda la información que se hace visible en función de la alta resolución de la imagen producida por el drone. Como resultado de este taller se corroboró que el asentamiento contaba en ese entonces con 270 polígonos identificados, lo que primeramente fue asociado al número de viviendas existentes en la comunidad. 


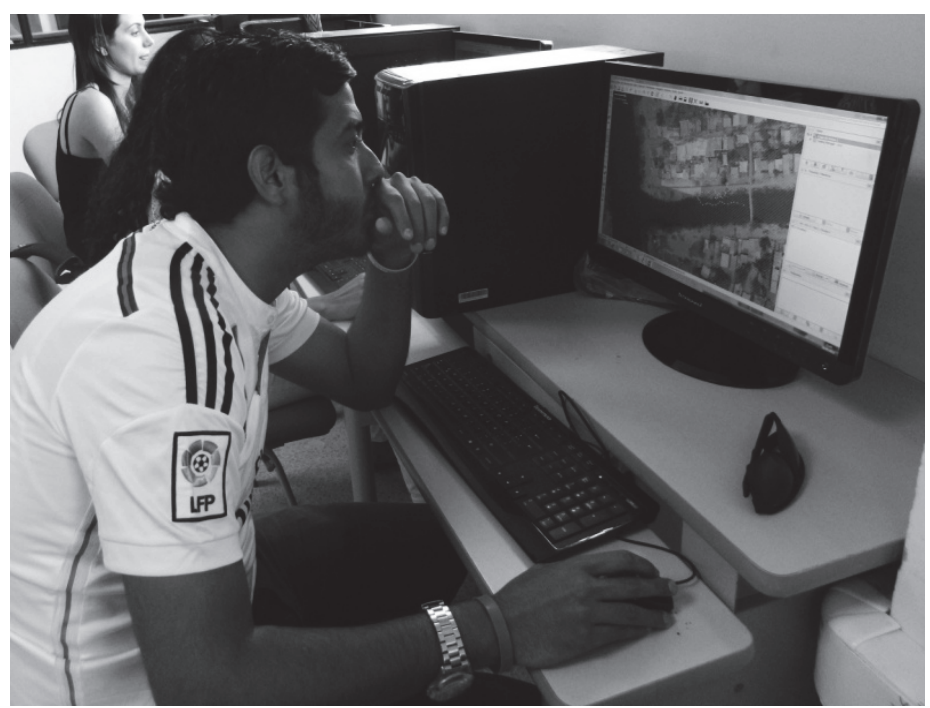

Figura 8. 2do. Taller de Mapeo, mapeando el presente.

Fuente: MAP Cartagena.

\section{Captura de datos geográficos en campo}

Para el levantamiento de datos en campo se usó como principal método Field Papers, una herramienta web desde la cual se generan mapas y atlas para imprimir divididos en cuadrantes, cada cuadrante es una hoja (tamaño carta u oficio) donde se van realizando anotaciones de los detalles encontrados en campo y que no pueden ser capturados desde una imagen aérea, tales como los comercios o nombres de las calles. También se valida la información generada desde el mapeo de escritorio o "armchair mapping" realizado en los talleres anteriores. Cada hoja impresa tiene un código QR que, tras ser escaneada y subida nuevamente en la plataforma de fieldpapers.org, georreferencia automáticamente la imagen, de forma que posteriormente pueda ser llamada desde el editor de mapas JOSM para la digitalización de los datos escritos en el papel.

Los voluntarios de TECHO junto con los pobladores corroboraron la existencia de cada vivienda, enriqueciendo la cartografía con información local, adicionando la existencia de tiendas, iglesias, bancas, árboles, puntos de toma de agua y baños comunitarios. Se identificó el estado actual de los polígonos anteriormente considerados como viviendas habitadas; algunas de estas estaban en estado de construcción, completamente abandonadas o incluso en proceso de venta. También se llevó cabo el ejercicio de nombrar las calles del asentamiento, donde sus pobladores fueron protagonistas, brindando su opinión y votando por el nombre de su preferencia. 


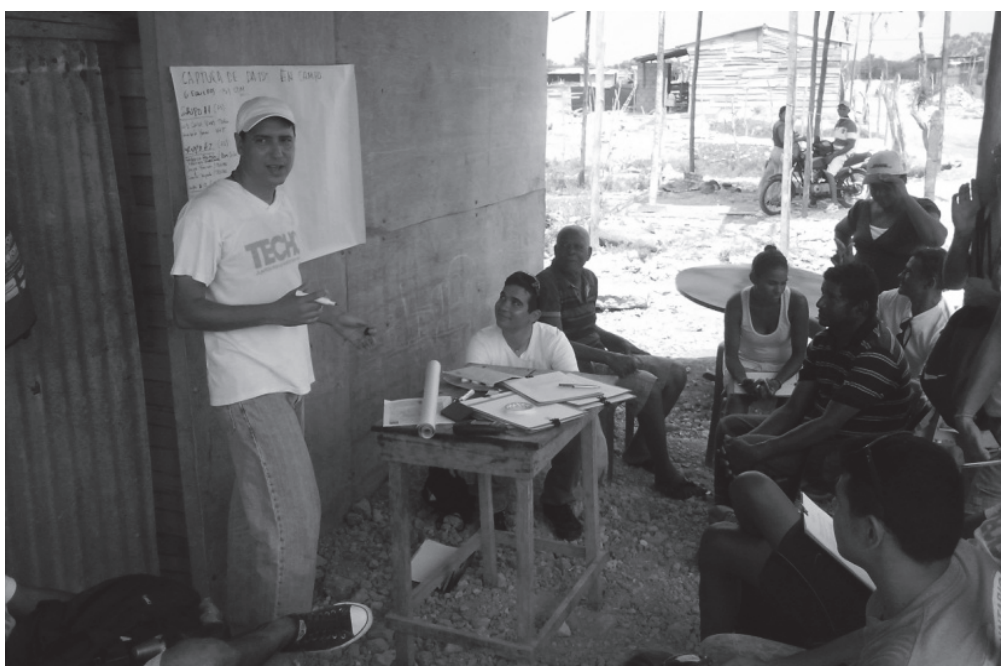

Figura 9. Taller Field Paper, definiendo etiquetas junto a la comunidad.

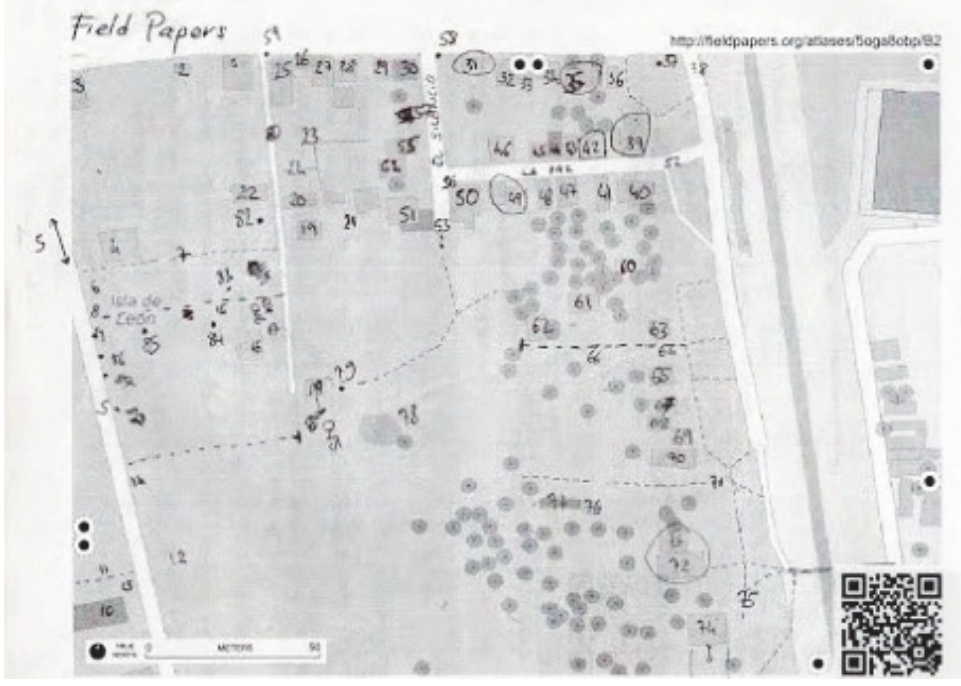

Figura 10. Hoja con las marcaciones del Field Paper.

\section{3er. Taller de Mapeo}

El tercer y último taller de mapeo tuvo como objetivo actualizar la cartografía del asentamiento por medio de los datos obtenidos con Field Paper y las trazas GPX capturadas desde teléfonos celulares y GPS, estas últimas utilizadas para confirmar la creación de nuevas calles y senderos, inexistentes en la imagen aérea del 15 de abril. 
Como resultado de la actividad, además del nombramiento de las calles, se actualizó la información sobre el estado de cada polígono: de los 270 polígonos citados anteriormente - fruto del 2 do. taller de mapeo-, 238 eran viviendas habitadas; casi el doble de las 120 que inicialmente plantearon los líderes comunitarios.

\section{Exportación y publicación de datos geográficos}

Al final de cada taller - luego de subir los nuevos datos—- la cartografía iba siendo automáticamente actualizada en OpenStreetMap. Para la exportación de los datos se trabajó con el programa "opensource" Quantum GIS, desde el cual es posible descargar directamente los datos de OpenstreetMap por medio de un plugin. A manera de ilustración, existen múltiples formas de exportar los datos de OpenStreetMap, varios de estos métodos se detallan en la página $<$ http://planet.osm.org/>. El Humanitarian OpenStreetMap Team tiene a disposición del público el Export Tool $<$ http://export.hotosm.org>, desde el cual se pueden exportar los datos en múltiples formatos, inlcuso para colocar los mapas dentro de GPS.

Estos datos finalmente fueron creados en el SIG como capas en archivos shapefiles y publicados en la plataforma HDX de UN OCHA <https://data.hdx.rwlabs. org/organization/techo-colombia>.

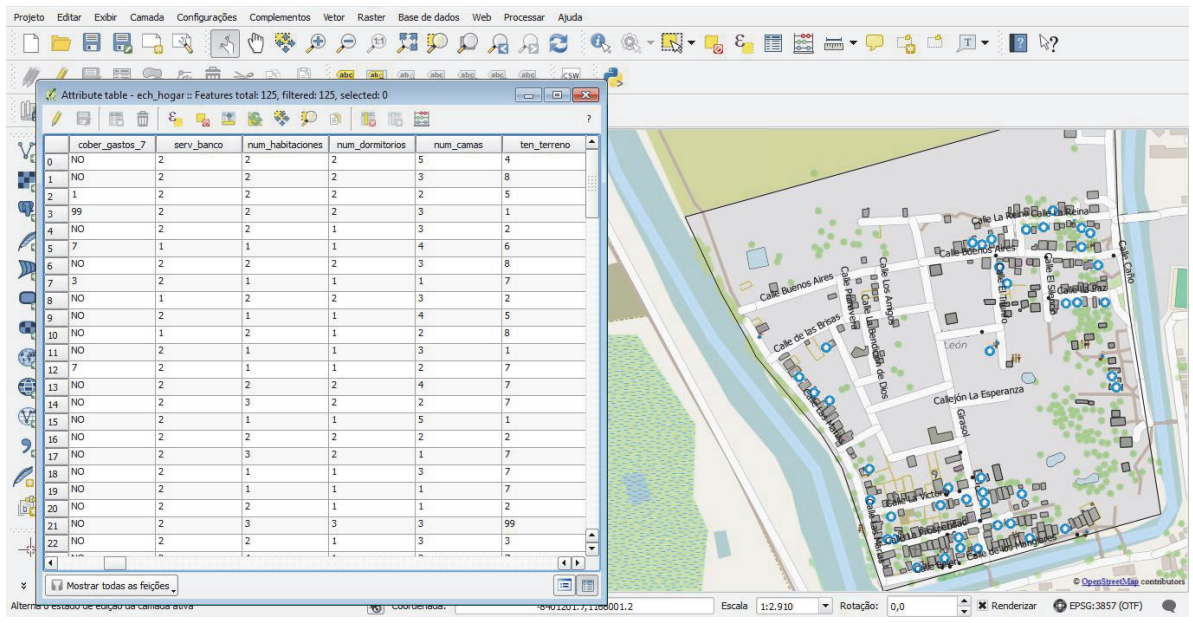

Figura 11. Pantallazo del SIG con todas las capas y tablas, el proyecto QGIS.

\section{La integración entre la cartografía y los datos poblacionales}

Debido a los objetivos del proyecto para que el componente cartográfico sirviera a la siguiente fase de intervención de desarrollo comunitario, era necesario integrar cada vivienda (como elemento espacial) con la ECH que le corresponde, de esta 
manera poder realizar un análisis de conjunto que evidenciara sus problemas más sensibles (véase Figura 11).

\section{Planeación de la encuesta en campo}

Para la ejecución de la encuesta en campo se decidió trabajar con un muestreo de la población total de viviendas, justificable por el tamaño de la comunidad, obviando la necesidad de un censo.

Para definir el tamaño de la muestra representativa se tomó como universo la población del número de viviendas contabilizadas en el tercer taller de mapeo (238). La selección de la muestra se definió por Muestreo probabilístico por conglomerado. Los conglomerados son áreas en las que se divide el terreno que ocupa la población de estudio, en función de alguna característica homogénea, el marco muestral fue subdividido entonces en cuatro áreas con similar número de viviendas. Al interior de cada conglomerado se procedió a un muestreo aleatorio simple. Para este proceso de muestreo fue creado un archivo shapefiles por cada una de las cuatro áreas, y el ID de las viviendas pertenecientes a cada una de las áreas fue sometido a un proceso de selección aleatorio. Los IDs seleccionados fueron numerados, esa numeración conformó el vínculo entre la vivienda a ser encuestada y su ubicación geográfica.

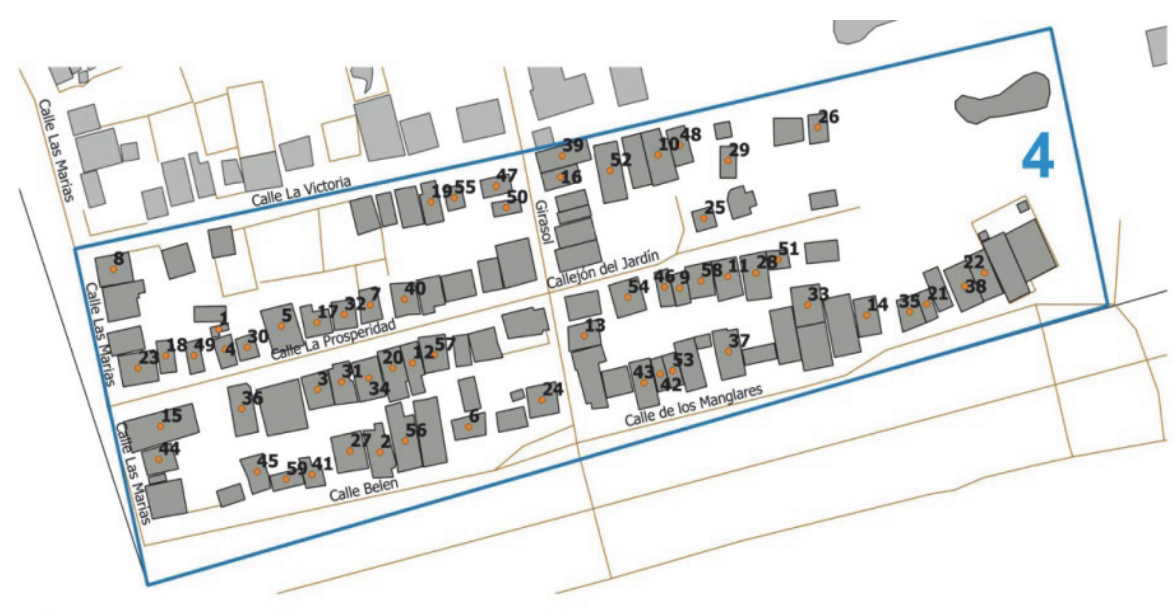

Figura 12. Delimitación de la zona 4 y la numeración de las viviendas seleccionadas.

\section{El encuestamiento a hogares}

La metodología implementada fue la Metodología de Caracterización de Hogares $(\mathrm{MCH})$, que viene siendo aplicada por TECHO desde el año 2014 (Manual de metodología de caracterización de hogares), cuyo objetivo principal es disponer de 
información que permita caracterizar la situación de los hogares y de la comunidad, de manera que sirva como insumo para la planificación del trabajo conjunto de la comunidad y TECHO, a la vez estimar la cobertura, focalización y distribución del trabajo mediante los principales programas y proyectos sociales.

La encuesta se compone de 10 módulos o secciones que permiten generar indicadores sobre: características generales del hogar y sus miembros, educación, salud, trabajo e ingresos, vivienda y servicios básicos, y comunidad.

A cada encuestador se le asignó un número de casas, se le entregó un mapa con las casas numeradas que le corresponden y los juegos de encuestas. Al momento de iniciar la encuesta este escribe el número de la casa en una casilla dispuesta en el formulario. La aplicación de la encuesta se dió en una actividad de encuestamiento masivo desarrollada en dos días consecutivos, donde se involucraron un gran número de voluntarios y de pobladores.

\section{La tabulación y uniones en el SIG}

Las encuestas fueron tabuladas y luego estas tablas se unieron a los polígonos de la vivienda, como la numeración origen de cada casa viene desde el SIG y en la tabulación de la encuesta existe una variable con el número de la casa, este se convirtió en la llave de unión entre ambos conjuntos de datos, permitiendo hacer análisis de las centenares de variables poblacionales en relación con la ubicación geográfica de cada vivienda.

\section{Resultados}

Los datos analizados permitieron generar 145 variables y 57 indicadores. Con la aplicación de la metodología explicada anteriormente fue posible georreferenciar estos resultados, generando mapas donde a cada vivienda se puede asociar la respuesta del cuestionario y mapas de calor para respuestas de incidencia, permitiendo un análisis territorial.

\section{Mediciones e indicadores}

Los siguientes fueron el tipo de mediciones e indicadores posibles de calcular gracias a la información geoespacial:

- Conteo de viviendas

- Área de la vivienda en metros cuadrados

- Área promedio de las viviendas en metros cuadrados

- Promedio de área por habitante de la vivienda 
112 Natalia da Silveira Arruda y Humberto Yances MAP Cartagena: metodología para el mapeo...

\section{Mapas}

Los siguientes son los mapas creados a partir de la unión de datos geográficos y poblacionales:

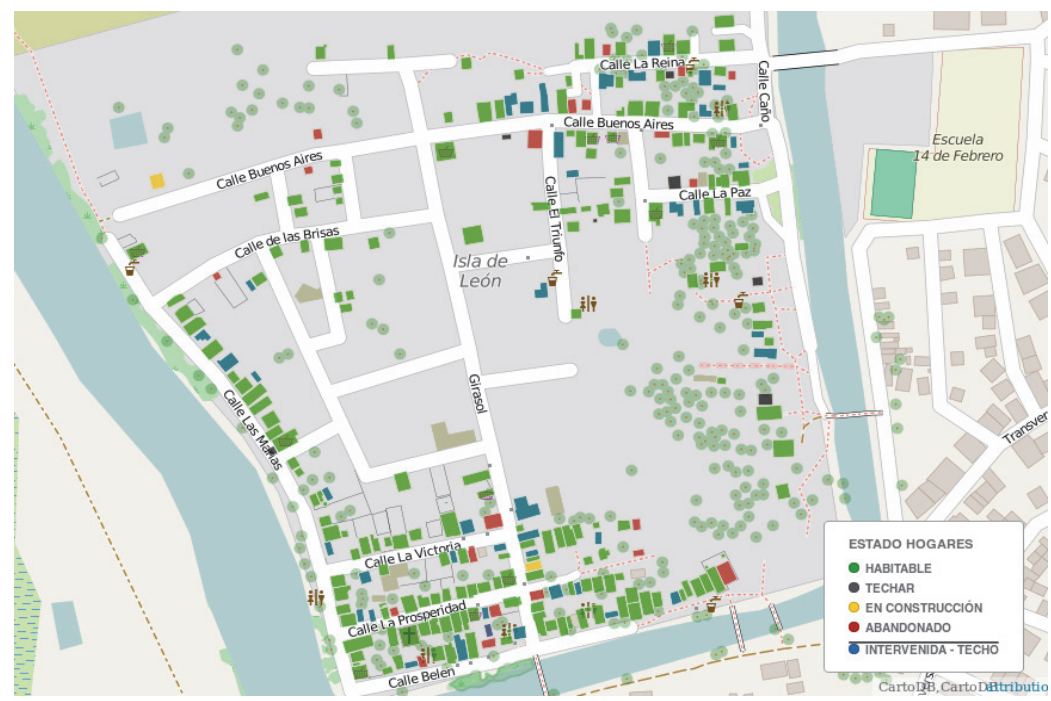

Figura 13. Mapa elaborado en CartoDB sobre el estado de las viviendas.

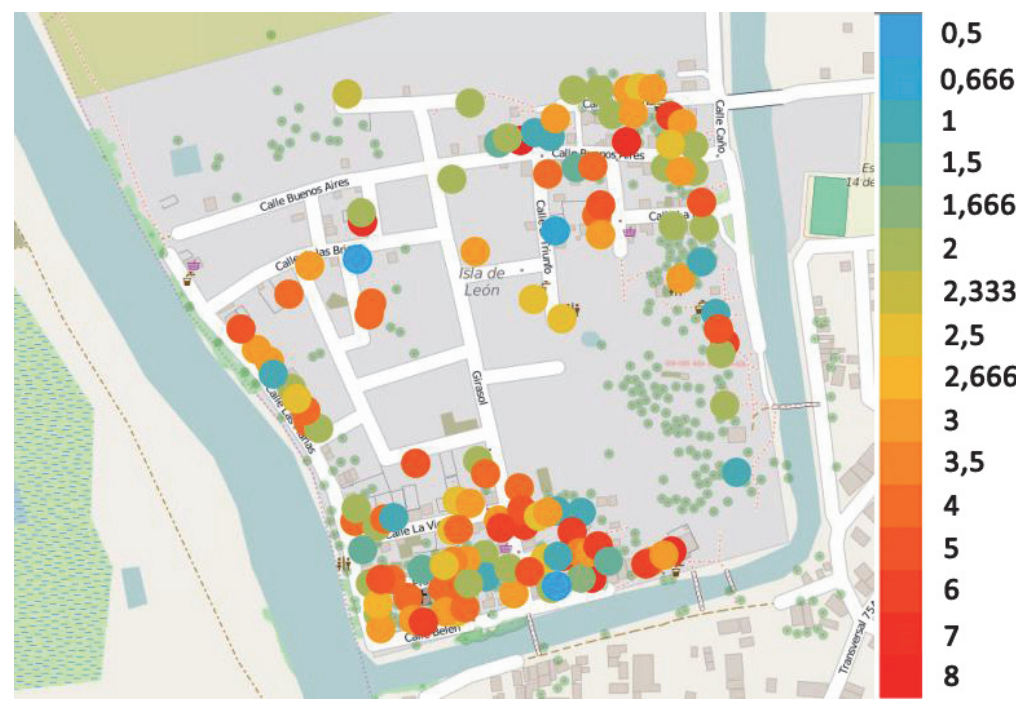

Figura 14. Nivel de hacinamiento: número de personas que duermen por cada cuarto de la vivienda. 


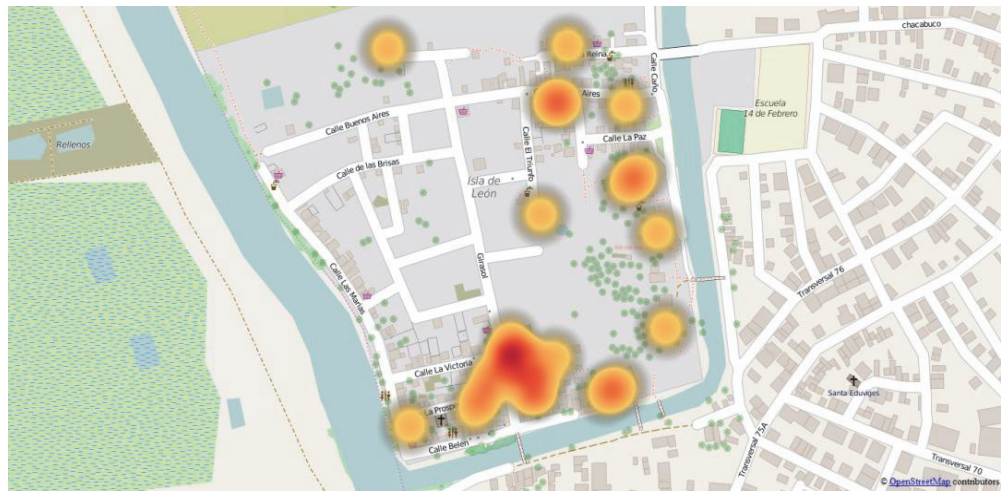

Figura 15. Mapa de calor: alumbrado público; respuesta: no tiene alumbrado público.

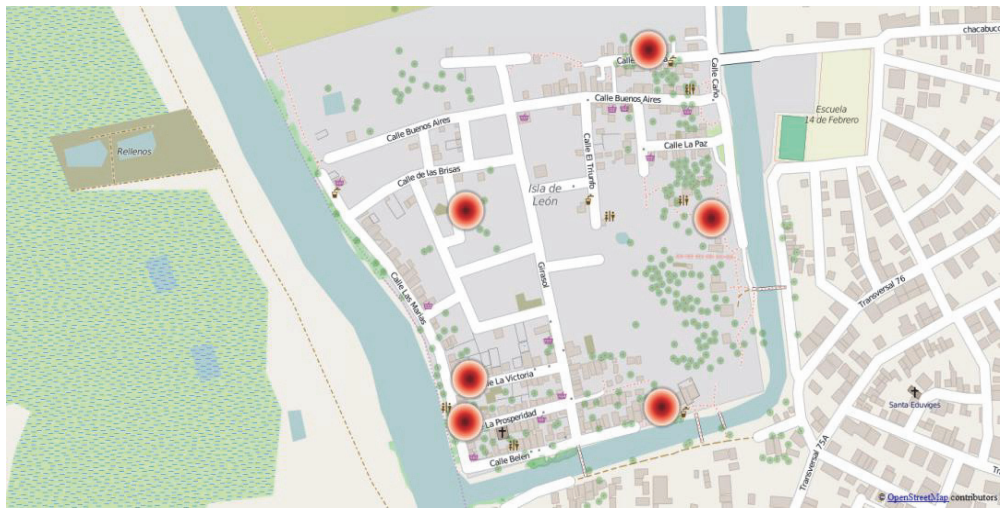

Figura 16. Mapa de calor: intento de desalojo en el último año; respuesta: sí.

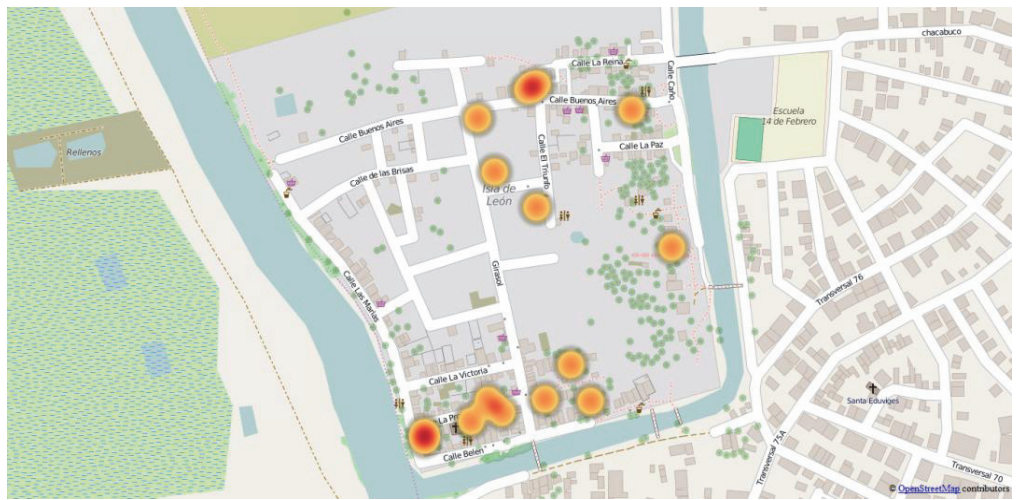

Figura 17. Mapa de calor: recolección de residuos; respuesta: informal colectado en uno o varios puntos dentro del barrio. 


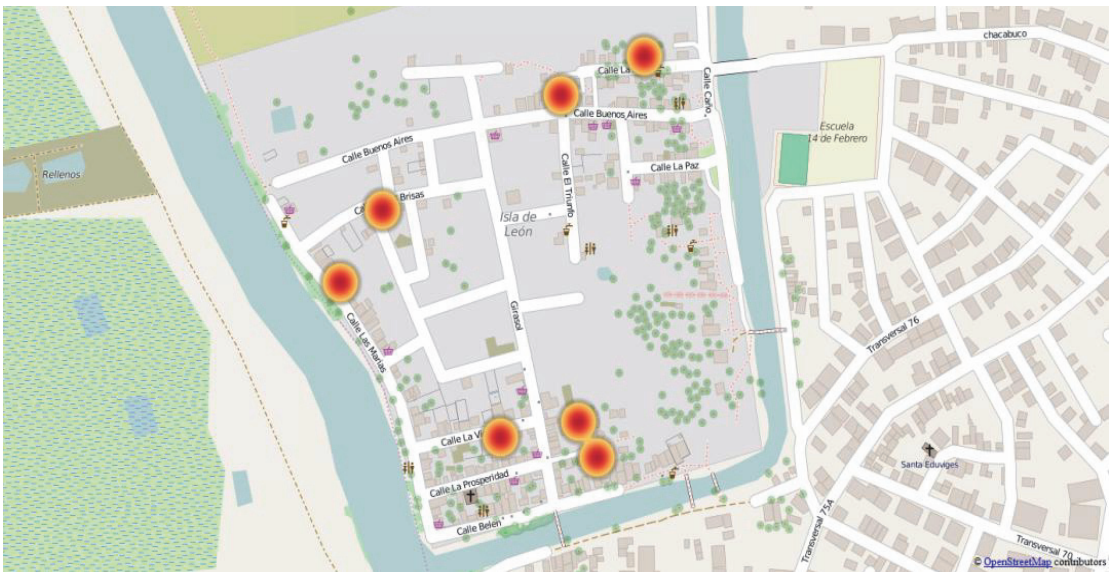

Figura 18. Mapa de calor: recolección de residuos; respuesta: formal colectado en uno punto dentro del barrio.

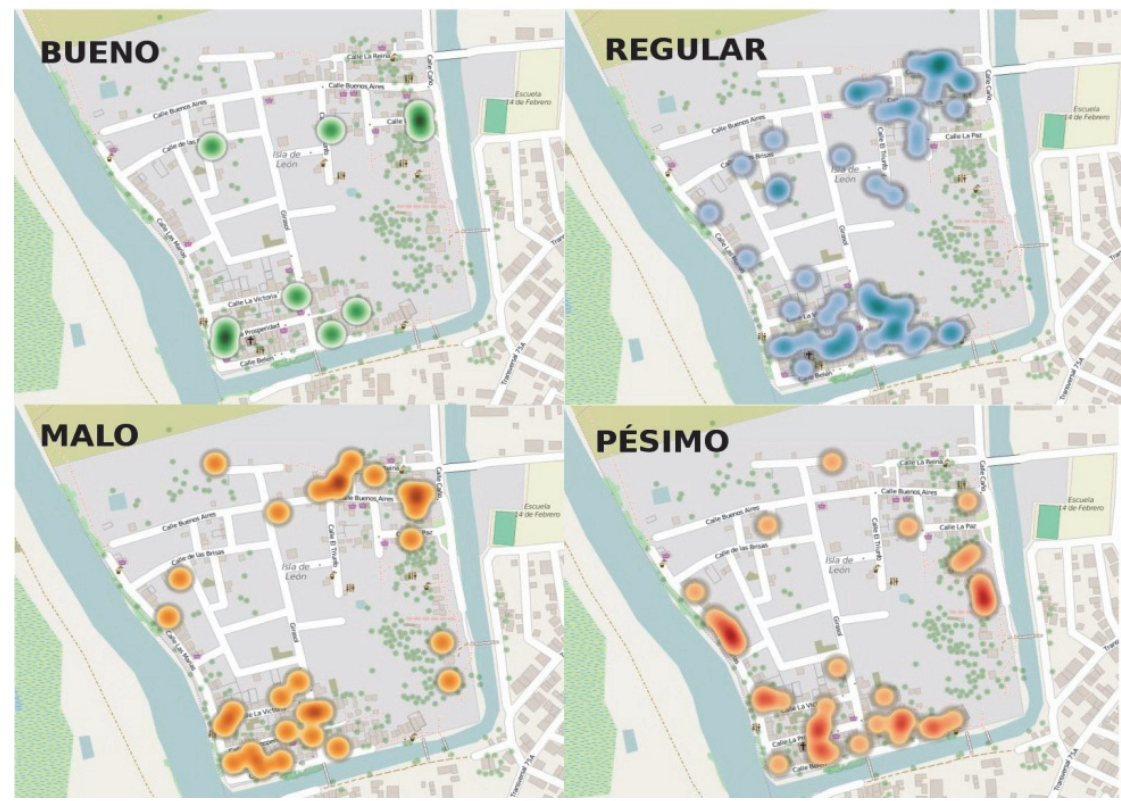

Figura 19. Percepción de calidad sobre el estado de las vías.

\section{Conclusión}

La metodología estructurada durante la experiencia del proyecto piloto MAP Cartagena tiene una aplicación innovadora en América Latina en el campo de mapeo de 
asentamientos informales. Innovación que reside en la unión de las metodologías de trabajo de TECHO y de HOT y de sus respectivas herramientas.

Los conocimientos y la metodología de trabajo desarrollados por HOT permitieron la georreferenciación de todas las fases del proyecto y la visualización de los resultados de manera rápida y práctica. La metodología que se lleva a cabo a través de los talleres de mapeo permite la actualización cartográfica en un intervalo temporal que poco depende del tamaño del asentamiento — dependiendo más bien de la cantidad de personas involucradas en cada taller — con excepción de la actividad de recolección de datos en campo.

Tratándose de un piloto - además de su rol como validador de ciertas actividades-, se aprendió con los errores: la actividad de encuestamiento fue hecha de manera manual y como consecuencia exigió un periodo excesivamente largo de digitalización de los datos para posterior análisis.

El trabajo de la ONG en el asentamiento permitió que el proyecto contase con un conocimiento previo de la comunidad y una presencia en campo a lo largo de todo el proyecto, a través de la participación de la misma comunidad y del voluntariado. Condiciones esenciales para que pudiera haber un proceso participativo y un consecuente aumento en la probabilidad de que el sentido de pertenencia les incentive a apoderarse de los resultados del proyecto y los utilicen en pro de su futuro desarrollo.

El soporte de los pobladores de Isla de León al proyecto piloto es una oportunidad de aplicar de manera práctica una metodología que pretende poder ser replicada en cualquier asentamiento informal y/o precario que presenta características semejantes sea por la falta de información cartográfica sea por la ausencia de datos que permitan su caracterización socio-económica.

Súmese a lo anterior, que la experiencia de mapeo de HOT aportó al proyecto la posibilidad de generar datos abiertos. Conocimiento que debe ser compartido y cada vez más reconocido como necesario en la búsqueda de la superación de las brechas sociales por ciudades más resilientes y equitativas.

\section{Bibliografía}

Arcieri G.V. (10 de julio de 2005), "Robo impune de Ciénaga de la Virgen", Diario El Tiempo, disponible en <http://www.eltiempo.com/archivo/documento/ MAM-1959670>, accedido el 21 de febrero de 2015.

Brito, P.B. (7 de junio de 2008). "En el olvido están sumidos habitantes de Isla de León, sector del barrio El Pozón (Cartagena)", Diario El Tiempo, disponible en $<$ http://www.eltiempo.com/archivo/documento/CMS-4240667>, accedido el 15 de octubre de 2015.

PNUMA (2009). Perspectivas del medio ambiente urbano: Geo Cartagena, Cartagena de Indias. 
Cartagena Cómo Vamos. - CCV (2014). Resultados evaluación calidad de vida 2013, Cartagena.

Cobos, A.G. (2003). "Cartagena de indias. asentamientos informales en la década de los 90". Bitácora urbanolterritorial, vol. 1.

Colnodo (2000). "Informe final del Proyecto Georreferenciación local: una herramienta para la toma de decisiones administrativas y de inversión", Bogotá.

Ministerio de Educación Nacional. Sistema Nacional de Indicadores: tasa de analfabetismo, disponible en <http://menweb.mineducacion.gov.co/seguimiento/ estadisticas/principal_ind.php?seccion $=23 \& i d$ _categoria $=4 \&$ consulta $=$ ind_tsa ana\&nivel $=23 \& d p t o=\&$ mun $=\&$ ins $=\&$ sede $=>$, accedido el 20 de octubre de 2015.

ONU-Habitat (2014). “Construcción de ciudades más equitativas: políticas públicas para la inclusión en América Latina”, Nairobi, Programa de las Naciones Unidas para los Asentamientos Humanos.

ONU-Habitat (2012). "Estado de las ciudades de América Latina y el Caribe 2012Rumbo a una nueva transición urbana", Nairobi, Programa de las Naciones Unidas para los Asentamientos Humanos.

Pedraza, M. (s.f.). "Robo impune de la ciénaga de la Virgen”, Diario El Tiempo disponible en <http://www.eltiempo.com/archivo/documento/MAM-1959670>, accedido el 16 de abril de 2015.

TECHO Argentina (2013). "Relevamiento de asentamientos informales 2013", Buenos Aires, TECHO.

TECHO (s.f.). TECHO Cartagena, disponible en <http://www.techo.org/colombia/ techo/regiones/cartagena/>, accedido el 08 de Setembro de 2014.

The World Bank (2014). “Open Data for Resilience: Planning an Open Cities Project", Washington DC, The World Bank.

Yances, H. (13 de abril de 2013). "La Boquilla Project", blog personal de OpenStreetMap, disponible en <https:/www.openstreetmap.org/user/Humber to_Yances/diary/19065>, accedido el 12 de febrero de 2016. 